\title{
The Increasing of Body Mass Index and The Pes Cavus have a higher prevalence of the Plantar Fasciitis In the Elderly
}

\author{
Indah Margaretha Masela, Titi Moertolo, Kirana Anggraeni \\ Faculty of Medicine, University of Trisakti
}

\begin{abstract}
Introduction : The Plantar fasciitis (PF) is an increasing degenerative process of the plantar fascia in elderly. The study has proven that PF has related to the body mass index (BMI) and the foot posture. The study aimed was to identify the relationship between the BMI and the foot posture, with the incidence of PF in the elderly that lived in a nursery home.
\end{abstract}

Method : The design study was the cross-sectional. A footprint assessed the foot posture. The BMI was measured by divided the body weight $(\mathrm{Kg})$ with the body height square $\left(\mathrm{M}^{2}\right)$. The foot posture was examined by foot print by ink on a papper. The degree of plantar fasciitis assessed by the score of the Foot Function Index (FFI). Statistical analysis was univariate and bivariate analysis by the Kruskal-Wallis test.

Result : There was a correlation between the BMI and the plantar fasciitis $(\mathrm{p}=0,029)$. However, there was no correlation between the foot posture and plantar fasciitis $(\mathrm{p}=0,280)$. Otherwise the foot posture of pes cavus has the highest of the FFI score (60.92).

Discusion :The increasing of BMI has the higher prevalence of the plantar fasciitis in the elderly. Furthermore, the foot posture of Pes cavus has a higher prevalence in plantar fasciitis among foot postures.

Keywords : Pes planus, pes cavus, body mass index, plantar fasciitis, elderly.

\section{Correspondence Detail:}

Indah Margaretha Masela

Email: Indahcakamata@yahoo.com 


\section{INTRODUCTION}

Plantar fasciitis is a plantar fascia degenerative syndrome due to recurrent trauma in the calcaneus area. ${ }^{1-3}$ This condition is the most common cause of heel pain. The caused was usually a biomechanical pressure. ${ }^{2-5}$ The Plantar fascia is a plantar aponeurosis that was located superficially between the muscles of the foot surface. ${ }^{3,4}$ The functions of the plantar fascia is to maintain the medial longitudinal arch (MLA) of the foot during gait movement, and as a support for shock absorption. ${ }^{6,7}$ The MLA has a prior role of the foot, that is to synergize between muscles on normal gait movement. ${ }^{6,7}$ The prevalence of plantar fasciitis was one from ten found in women aged 40-60 years. ${ }^{1-3}$

Some factors can lead to the incidence of plantar fasciitis, namely increasing of the Body mass index (BMI), and foot deformities (pes planus and pes cavus) ${ }^{8,9}$ The earlier study has proven that $70 \%$ of patients with weight gain and $81-86 \%$ with excessive pronation experience plantar fasciitis. ${ }^{9} 10$ The Pes planus is the prevalence abnormality of the foot posture, there was $10-20 \%$ in the population. The foot posture with the lower or no MLA on foot, and associated with the rear foot eversion, excessive pronation of the subtalar joint, as the results were increased the tension on muscles around the joint, ${ }^{6,7}$ tighten the plantar fascia, and become the risk of the Plantar Fasciitis. ${ }^{11,12}$ The Pes cavus is afoot posture that has a rigid high medial arch structure, which caused narrowing the distance between front to rear foot. This foot posture has a malfunction during load distribution, that has an impact on the shock absorption, followed by reducing foot balance during standing, and finally increase the pressure on the plantar fascia. The Body weight has well known as on of the indicators that can be used to evaluate the nutritional status. ${ }^{9}{ }^{10}$ On the other hand, increasing of the body weight has caused the pressure on the plantar fascia during the stance phase resulting. ${ }^{910}$ The other factors that affect the incidence of plantar fasciitis are biomechanical and environmental factors. The biomechanical process of the plantar fascia occurs when the metatarsophalangeal joint extension (MTP) produces tension in plantar aponeurosis. Plantar fascia tension can also come from environmental factors, which are the result of long-standing activities on a hard surface, or a long distance of walks without using the footwear. ${ }^{13-15}$

Furthermore, the degenerative process associated with gradually reduced of the collagen and the fluid, that has an impact on decreases of the elasticity of the plantar fascia fat pads. As a result, was reduced the capacity of pressure absorbed, and then caused stiffness on the plantar fascia while walking, then continued to a progressive degenerative process. ${ }^{16}$ There are several methods of plantar fasciitis management, i.e., by light therapy, using orthotic footwear, and exercise. ${ }^{17-19}$

\section{METHOD}

This study used an analytic observational type of research with the cross-sectional method. This study conducted in March-July 2018 at the social institution of Tresna Werdah Budi Mulia 2. The sample selected 
by simple random sampling. The foot posture was examined by ink foot print on the white paper. The body weight was measured by the Body Mass Index (BMI) that divided body weight (Kg) with a square height weight $\left(\mathrm{M}^{2}\right)$. The assessment for plantar fascitis was by the Foot Function Index (FFI) questionnaire. The statistical analysis used for univariate analysis for frequency distribution, and bivariate analysis for analyzed the relationship between the two variables by the Kruskal-Wallis test.

\section{RESULTS}

The list of data on Table 1 has shown there were 104 respondents, that most of the subjects were female, aged between 60-74 years. Fifty-eight percent of the subjects had normal foot posture, and $48 \%$ has normal BMI. The most prevalence for the FFI was the score of 8-30.

\section{Table 1.}

\begin{tabular}{lcc}
\hline Characteristics & $\begin{array}{c}\text { Frequency } \\
\text { (n) }\end{array}$ & $\begin{array}{c}\text { Percentage } \\
(\%)\end{array}$ \\
\hline Sex & & \\
$\quad$ Male & 48 & 46,2 \\
$\quad$ Female & 56 & 53,8 \\
Age & & \\
60-74 & 82 & 78,8 \\
$75-90$ & 19 & 18,3 \\
>90 & 3 & 2,9 \\
Foot Shape & & \\
Normal & 58 & 55,8 \\
Pes Planus & 27 & 26,0 \\
Pes Cavus & 19 & 18,3 \\
Body Mass Indeks (BMI) & & \\
Underweight (14-18,5) & 20 & 19,2 \\
Normal (18,5-22,9) & 48 & 46,2 \\
Risk (23-24,9) & 16 & 15,4 \\
Obese type I (25-29,9) & 11 & 10,6 \\
Obese type II (30-34) & 9 & 8,7 \\
Foot Function Indeks (FFI) & & 76,9 \\
8-30 & 80 & 17,3 \\
31-60 & 18 & 5,8 \\
61-87 & 6 & \\
\hline
\end{tabular}

\section{Bivariate analysis}

The data from Table 2 revealed the Relationship between the BMI with the FFI by the Kruskal-Wallis test revealed. There were correlates with variables $(p=0.029)$. The post hoc statistic test was needed by the 
Mann Whitney U tests, to find out the differences between the BMI categories on the FFI score. The test results showed that the FFI score was higher in the obese II group compared by the normal group ( $\mathrm{p}=$ $0.006)$, by the risk group ( $p=0.027)$, as well as compared by the obese I group $(p=0.001)$.

Table 2.

\begin{tabular}{lcc}
\hline \multicolumn{1}{c}{ BMI } & FFI & p \\
\hline Underweight $(\mathrm{n}=20)$ & 56,00 & 0,029 \\
Normal $(\mathrm{n}=48)$ & 51.49 & \\
Riks $(\mathrm{n}=16)$ & 45,69 & \\
Obese type I (n=11) & 38,41 & \\
Obese type II $(\mathrm{n}=9)$ & 79,44 & \\
\hline
\end{tabular}

The relationship between the foot posture with the FFI score has shown in Table 3. There was no correlation between the foot posture with the FFI score $(p=0.280)$. However, the list of data has shown that the frequency of pes cavus foot posture has the highest mean score compared to the healthy foot posture and pes planus foot posture (60.92). The data has revealed that on the pes cavus foot posture has the highest incidence of the plantar fasciitis compared to the healthy foot posture and pes planus foot posture

Table 3.

\begin{tabular}{lcc}
\hline \multicolumn{1}{c}{ Foot shape } & FFI & P \\
\hline Normal $(\mathrm{n}=58)$ & 48,72 & 0,280 \\
Pes Planus $(\mathrm{n}=27)$ & 54,70 & \\
Pes Cavus $(\mathrm{n}=12)$ & 60,92 & \\
\hline
\end{tabular}

\section{DISCUSSION}

This study has a result that there was a correlation between the BMI with the Plantar Fasciitis, which the higher of the BMI has, the higher incidence of the Plantar Fasciitis. This result agreed with the earlier study by Putu Adi Merta in Gianyar Bali Island, that study the correlation between Body Weight with the Plantar Fasciitis on young women. The study has found that higher of Body Weight correlates with the higher incidence of the Plantar Fasciitis. ${ }^{10}$ Although the study conducted on the younger age, the result can be used as an explained on the elderly population. The higher BMI has consequences for increasing the load and tension to the weight bearing on the body. ${ }^{9,10}$ The one the weight bearing organ that can be affected was the foot, besides the knee and the hip organ. ${ }^{6,7}$ This study has supported the knowledge that the higher BMI has an impact on the severity of the Plantar Fasciitis. 
6. Rachmawati MR, Tulaar ABM, Immanuel S, et al. Correcting of pronated feet reduce skeletal muscle injury in young women with biomechanical abnormalities. Anatomy \& Cell Biology. 2016;49(1):15-20. doi:10.5115/acb.2016.49.1.15.

7. Chimenti R, Tome J, et al. Adult-Acquired Flatfoot Deformity and Age-Related Differences in Foot and Ankle Kinematics During the Single-Limb Heel-Rise Test. J Orthop and Sports Phys Ther. $2014 ; 44 ; 4 ; 283$

8. Thomas, K W Johan, Henhy. Sistem pengukuran berat badan dan tinggi badan menggunakan mikrokontroler AT89S51. Tesla 2008;10:79-84

9. Narredy J S, Reddy V S. Prevalence of plantar fasciitis and calcaneal spur in obese diabetics-a cross sectional study. IJAR 2015;2:8:32

10. Merta P A, Winaya M N, Sugiritma W. Perbandingan antara massa tubuh kategori normal, overweight, dan obesitas dengan resiko mengalami plantar fasciitis pada wanita usia dewasa dikecamatan gianyar. Majalah Ilmiah Fisioterapi Indonesia. 2018;6;2:31

11. Wenzel E M, et al. Prevalence of equines in patients diagnosed with plantar fasciitis. The Foot and Ankle Online Journal. 2009;2;3.

12. Cacace LA, et al. The association between pes planus foot type and the prevalence of foot disorders the fremingham foot study. Osteoarthritis and Cartilage. 2013

13. Thompson J N, Saini SS, Reb C W, Daniel J N. Diagnosis and management of plantar fasciitis. J American Osteopath Assoc. 2014;114:12:900-1

14. Dabadghav R. Plantar fasciitis: a concise view on physiotherapy management. Clin Res Foot Ankle. 2016;4:4:1

15. Ball T. Butler M. Parsons S. Pes cavus- not just a clinical sign: diagnosis, aetiology, and management. Rehabilitation article. 2013; 12:6:16-18

16. Tahririan M A, Motififard M, Tahmasebi M N, Siavashi B. Plantar fasciitis. J Res Med Sci. 2012;800

17. Lurati A R. Flat feet and a diagnosis of plantar fasciitis in a marine corp recruit. Workplace Health \& Safety. 2015.;63:4:137

18. Guffey J, Head P, Kaloghirou A. Effects of light on pain and function in patients with plantar fasciitis. J Athl Med. 2013;1:1:38

19. Banwell H A, Mackintosh S, Thewlis D, LandorfK B. Consensus-based recommendations of Australian podiatrists for the prescription of foot orthoses for symptomatic flexible pes planus in adults. J Foot and Ankle Res. 2014;7:49:1 
The study has found although the statistically revealed that there was no correlation between the foot posture with the FFI score, the data has shown that the Pes Cavus foot posture has the highest score of the FFI. The study data described that on the Pes Cavus foot posture has a higher incidence of the Plantar Fasciitis. This result supported the previous study by Wenzel E.M in 2009; the pes cavus foot posture had the highest incidence of the Plantar Fasciitis, compared by Normal and Pes Planus foot posture. ${ }^{11}$ Another study by Cacace L.A has the same result as well. ${ }^{12}$ The biomechanically can be explained, that on the Pes Cavus foot posture has a narrow distance between fore and rear foot, that increased the tight of the Plantar Fascia and reduced the elasticity between joints of the foot while standing or walking. The lack of foot elasticity may have an impact on increasing the inflammation of the Plantar Fascia. ${ }^{1-3}$

This result study has supported the knowledge that on the Pes Cavus foot posture has a higher risk to the Plantar Fasciitis.

\section{CONCLUSION}

The higher of the BMI correlates with a higher incidence of the Plantar Fasciitis, and the Pes Cavus foot posture has the higher incidence of the Plantar Fasciitis on elderly in nursing home.

\section{ACKNOWLEDGMENT}

My highest gratitude to all dedicated Subjects from the Panti Social Tresna Werdha-2 (PTSW-2) to participated in this study, to management and all of the staff of the PTSW-2 nursing home that has cooperated and open arm to facilitation this study, and to all my honored Lectures from Faculty of Medicine, University of Trisakti, Jakarta.

\section{REFFERENCES}

1. Gautham P, Nuhmani S, Kachanathu S J. Plantar fasciitis: a review of the literature. Saudi J Sport Med. $2014 ; 14: 2: 70$

2. Ferreaira R C. Talagia: plantar fasciitis. Rev Bras Ortop. 2014;49:3:214

3. Kalniev M A, Krastev D, Krastev N, Vidinov K, Valtchev L, Mileva M. Abnormal attachment between a plantar aponeurosis and calcaneus. Clujul Med. 2013;86:3:200-1

4. Pawar PA, et al. A study on effect of strain-counterstrain in plantar fasciitis. Int J Adv Med. 2017;4;2:5512

5. Kirby K A. Longitudinal arch load-sharing system of the foot. Rev Esp Podol. 2017;28:1:e18 